\title{
STRUCTURAL DYNAMICS OF CREATIVE ECONOMIES IN EMERGING TERRITORIAL SYSTEMS. CASE STUDY BUCHAREST-ILFOV DEVELOPMENT REGION
}

DOI: http://dx.doi.org/10.18509/GBP.2019.39

UDC: 338.46(498)

\author{
Andreea Karina Gruia ${ }^{1,2}$ \\ Alexandra Grecu ${ }^{1,2}$ \\ Marian Marin ${ }^{1,2}$ \\ Ion Andronache ${ }^{2}$ \\ Adrian-Gabriel Simion ${ }^{1,2}$ \\ ${ }^{1}$ University of Bucharest - Faculty of Geography, Romania \\ ${ }^{2}$ University of Bucharest - Research Center for Integrated Analysis \\ and Territorial Management (CAIMT), Romania
}

\begin{abstract}
The creative industry is developing today as a global phenomenon. The creative economy has vast potential for development and is one of the sectors with the fastest growing global economy. Creativity becomes the engine of social and economic change, turning into a new source of competitive advantage, as it is about how content creates creativity and helps create jobs. The study aims to analyze the spatial dynamics of creative economies at the level of Bucharest-Ilfov Development Region. A database was created, at the level of the administrative-territorial unit, with 2 economic indicators - the number of employees and the turnover considered relevant for this study, according to the NACE classification (Classification of National Economy Activities) for the period 2000-2016 on the basis of which has been made distribution maps of the creative economies for the Bucharest-Ilfov Development Region. Also, in order to quantify spatial dynamics of turnover and number of employees, in the study were tested: Sholl analysis (which quantifies the dynamics of the branching phenomenon), Mass Dimension (which measures the degree of "centrality"), Entropy (showing the degree of disorder), Pyramid Dimension (which shows the degree of complexity of the turnover relationship and the number of employees), Higuchi 2D (which shows the degree of complexity of the turnover relationship and the number of employees), Kolmogorov Complexity (which shows the degree of complexity of the phenomenon analyzed), FFI (indicating the dynamics of fragmentation / compaction of wealth or poverty). The obtained results show the specificity of the development of creative economies in the emerging spaces structured by highly complex urban systems.
\end{abstract}

Keywords: territorial systems, creative economies, spatial dynamics, regional distribution

\section{INTRODUCTION}

The origins of the creative sector are considered to be individual creativity, skill and talent. By generating and exploiting intellectual property, it helps to increase welfare and create jobs [1].

In recent years, the creative economy has become a powerful transforming force all over the world, and its role has grown significantly in society [2] and becoming one of the 
fastest growing sectors in the global economy [3]. Creative industries also have an important influence on the richness of a region [4]. Through culture, creative industries have become an essential milestone of modern post-industrial economies based on knowledge [5].

In analysis of digital images, is frequently used GLCM analysis, because GLCM functions characterize the texture of an image by calculating the density of pixel pairs with specific values in a spatial relationship specific to an image. This is done by creating a GLCM, then extracting the statistical dimensions from that array (providing information about the shape and spatial relationships of the pixels of an image) [6], [7], [8].

Fractal analysis is a relatively recent tool that allows analysis of chaotic data series [9], or images [10] whose objects do not fit into classical, euclidean geometry. The term fractal was introduced by Benoit Mandelbrot in 1975 [11], starting from the latin word "fractus", meaning "broken" or "fractured", and used it to extend the concept of theoretical fractional theorems to the geometric models of nature. Different fractal methods can be performed, including binary analysis, grayscale dimensions, color dimensions, and lacunarity analyzes.

The most common fractal analysis methods are: Ruler Dimension [12], [13], BoxCounting [14], [15], [16], Dilation Dimension [17], Mass Dimension [18], Local Connected Fractal Dimension [19], Perimeter-Area Dimension [20], [21], Information Dimension [22], [23], Minkowski Dimension [24], Higuchi 1D [25], Higuchi 2D [26], [27], FFT Dimension [28], Correlation Dimension [29], [30], Tug-of-War Dimension [31], Blanket Dimension [32], Multifractal Dimension [33], [34] or recently Fractal Fragmentation Index [35], [36], [37].

\section{METHODOLOGY}

The study of the distribution of creative economies at the level of Romania was achieved by creating an economic database at the level of the administrative-territorial unit with 2 economic indicators (number of employees and turnover) considered relevant for the creative economic activities according to the National Classification of Economic Activities (NACE), at the four-digit level for the period 2000-2016. Based on the data obtained, 17 maps were created for each indicator, using the open-source software QGIS 3.4. The maps were made in grayscale with 5 color classes (the smallest having the darkest color). The 8-bits grayscale images were segmented by extracting the 5 classes set in during GIS design.

Analyzes were made on binary images, resulting from the segmentation of the 5 classes of the image in gray tones and 8-bit grayscale images. Thus, Sholl Analysis and GPLM Entropy were made using the open-source ImageJ software [38], [39], Mass Dimension with Benoit 1.3. software [40], the rest of the analyzes being performed in open source IQM 3.5 [41].

Binary analyzes methods were performed on binary images, making 4 classes according to the grayscale class values (white color - over 60.000.000 lei / over 400 employees, light gray ranging from 10.000.001-60.000.000 lei / 101-400 employees, moderate gray ranging between 5.000.001-10.000.000 lei / 51-100 employees and dark gray ranging between 1.000.001-5.000.000 lei / 26-50 employees, so 01 (includes only the class with the most large values - white color), class 01-02 (includes the first two classes of values - white and light gray), 01-03 (includes the first three classes of values - white, light gray and moderate gray) and 01-04 (includes the first four classes of values - white, light gray, moderate gray and dark gray), the last class (the black one with the smallest values) is not 
included here. Analyzes include: Sholl analyzes [42] calculated the number of intersections per concentric shell, and the mean diameter of the dendrites or axons within each concentric shell. The analysis was made using Sholl analysis 3.6.2 [43], [44]. Mass Dimension, this fractal method can apply to objects that follow a certain radial symmetry, such as diffusion-limited aggregates (DLA). Dm measures the mass $m(r)$ in circles with increasing ( $\mathrm{r}$ ) concentric rays starting from the "center" of the object (image) (rmin) to the periphery ( $\operatorname{rmax})$. Then we plot the logarithm of $m(r)$ versus the logarithm of $r$. Mass Dimension and values between 1-2. When it tends to 1 it highlights chaotic, uneven, asymmetric development in several directions. When tending to 2 indicates symmetric, uniform development, in concentric "circles". Fractal Fragmentation Index or FFI (binary) [35] is a fractal index that measures fractal fragmentation. FFI is the result of the difference between the fractal dimension of areas (mass) and perimeters (border). IQMPlugin-FFI plug-in was used [45]. The Pyramid Dimension method is an alternative to Box-Counting Dimension and uses image pyramids that are a sequence of identical images, but at different sizes. The bottom of the pyramid is the original image. The image size is then reduced successively until it is a pixel representing the top of the pyramid [46], [47].

Textural analysis was done on 8-bit grayscale images. Thus, the FFI (grayscale analysis) was performed according to the methodology described in the binary analysis, with the words that FFI can also be used for grayscale analysis, and that Pyramid Dimension (PGM) is the Pyramid Gradient Method. Global IQM entropy and GLCM entropy show the degree of complexity of the texture of an image. The entropy is big when the image is not textural uniform and many GLCM elements have very low values. Complex textures tend to have great entropy. Global entropy and GLCM entropy was calculated [48] using IQM for Global Entropy and ImageJ for GPLM entropy. The Higuchi 2D method is based on calculating the fractal complexity of an image, taking into account pixel grayscale ratios relative to the gray values of proximal pixels [49, 50]. The kfoldDiff algorithm was used, with $\mathrm{k}=50$. Higuchi $2 \mathrm{D}$ contains values between 2-3. Grayscale 8bit images analyzed 2 Pyramid Dimension algorithms in average values: PGM (Pyramid Gradient Method) and KC (Kolmogorov Complexity) [51]. The Kolmogorov complexity of a fractal object represents the length of the shortest computer program in Kilobyte (KB) or Megabyte $(\mathrm{MB})$, in a predetermined programming language that produces the fractal object as output. It is known as algorithmic entropy [52]. The two algorithms were tested: the PNG algorithm (KC_PNG (MB)) and the ZIP algorithm (KC_ZIP (MB)).

\section{RESULTS}

Analyzing the distribution of the total turnover (Fig. 1) for the Bucharest-Ilfov Development Region, it can be observed an upward trend of values and a dominance in the hierarchy of the creative cities of Bucharest. In 2000 (Fig. 1A) Bucharest had a value of 5.739.656.152 lei (the highest in Romania and within the region), and Bucharest-Ilfov Region was the first of 8 with a value of 45.019.274.481 lei. Increases are observed even after the economic crisis, reaching in 2016 at the value of 527.830.760.316 lei, of which Bucharest held 48.214.176.698 lei (9.13\%). 

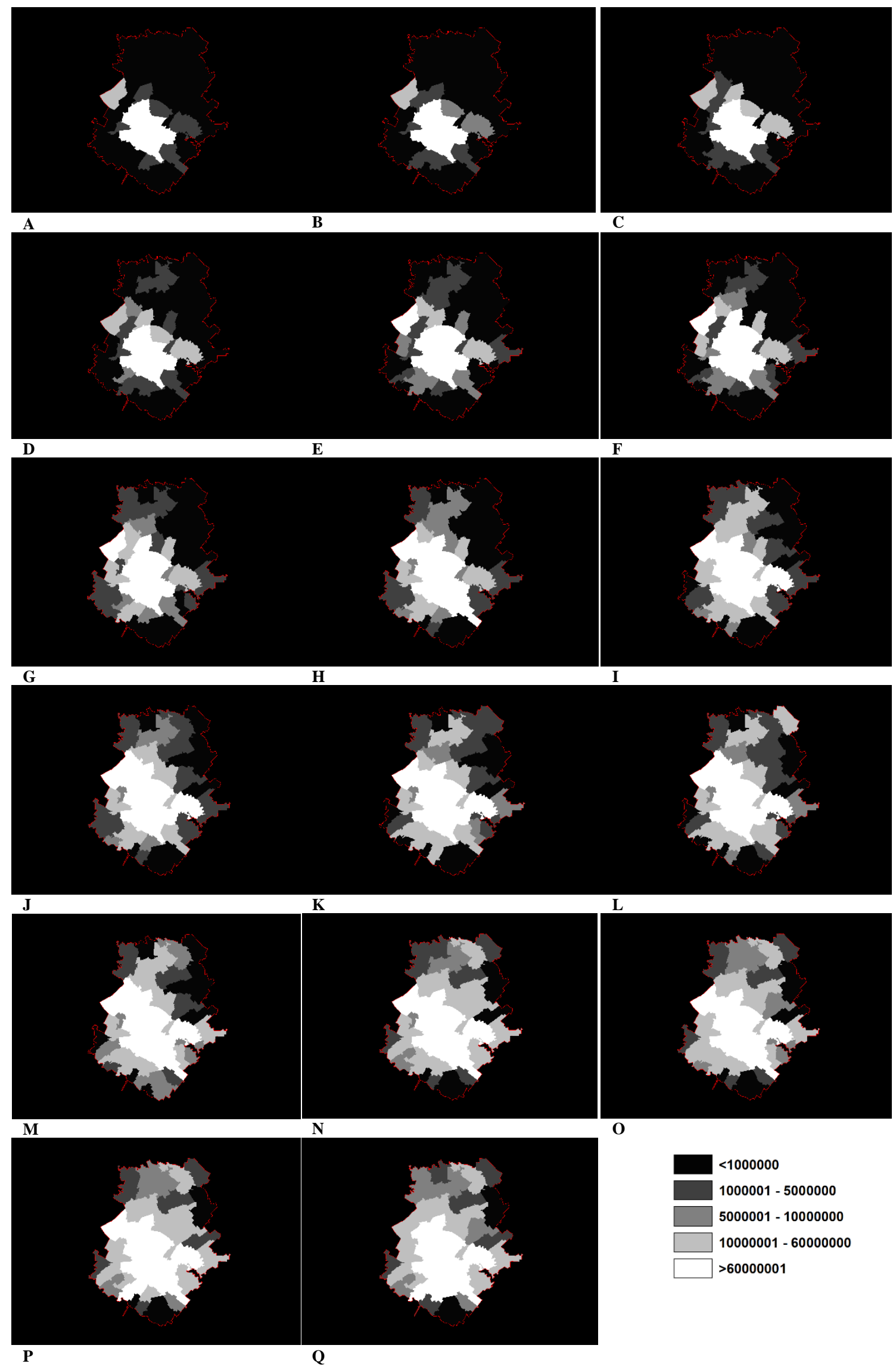

$\mathbf{O}$

\section{$<1000000$}

$1000001-5000000$

5000001 - 10000000

$10000001-60000000$

$>60000001$

Figure 1. Distribution of total turnover (lei) (A - year 2000 to $\mathbf{Q}$ - year 2016) 


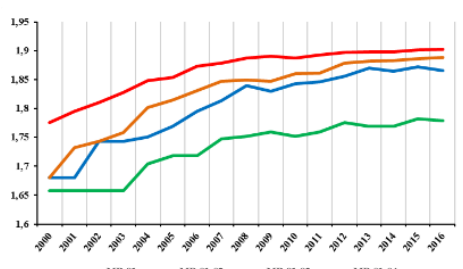

—

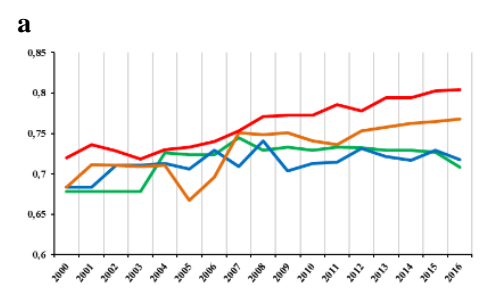

一rm

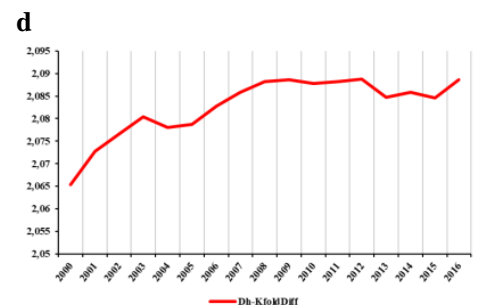

g

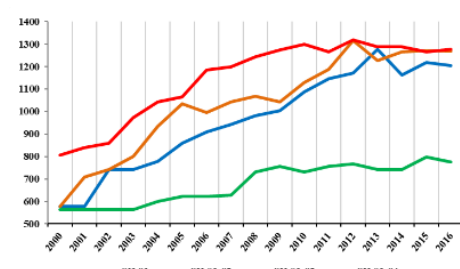

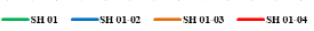
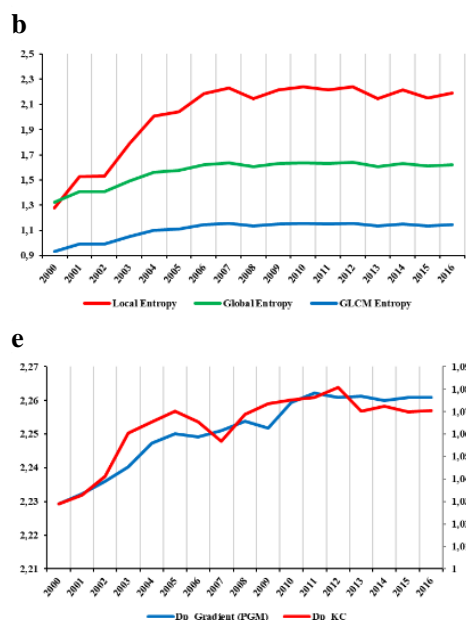

h
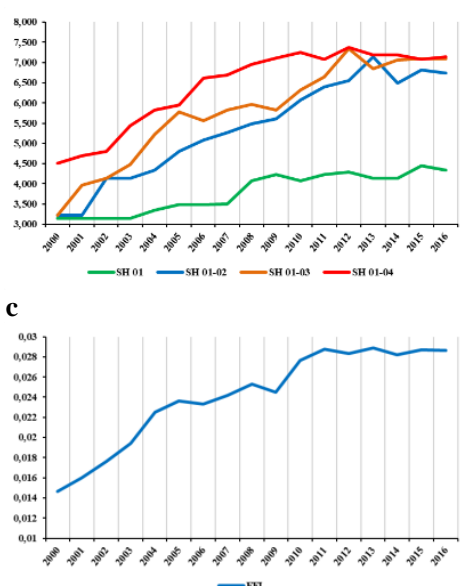

f

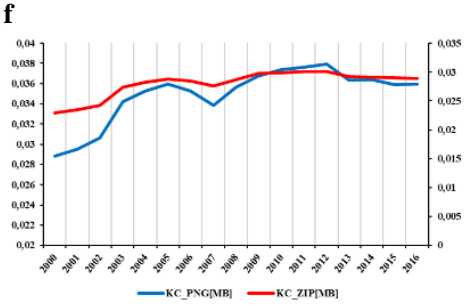

Figure 2. Dynamics of turnover. a. Mass Dimension; b. Sholl Dimension - number of intersections; c. Sholl Dimension - the mean of intersections; d. FFI binary; e. Entropy (local - red; global - green; GLCM - blue); f. FFI grayscale; g. Higuchi 2D; h. Pyramid Dimension (PGM - blue; KC - red) i.

Kolmogorov complexity (PNG - blue; ZIP - red)

The binary analyzes made on the cartographic models of the turnover distribution on the 4 classes highlight for Mass Dimension a spread of values to value 2, which indicates a symmetrical, uniform turnover development. Sholl analysis indicates a dynamic spacetime turnover dynamics for creative economies. The analysis went from pixel 0 (the center of Bucharest) to the 1970 pixel (the maximum outside), and the circles were in the number 179, being drawn from 10 in 10 pixels. The average was obtained by dividing the number of intersections in 179 circles. The value is in the increase in class 01-04, where new directions of propagation appear in the analyzed period. The analyzes of the other indicators confirm these trends (Fig. 2).

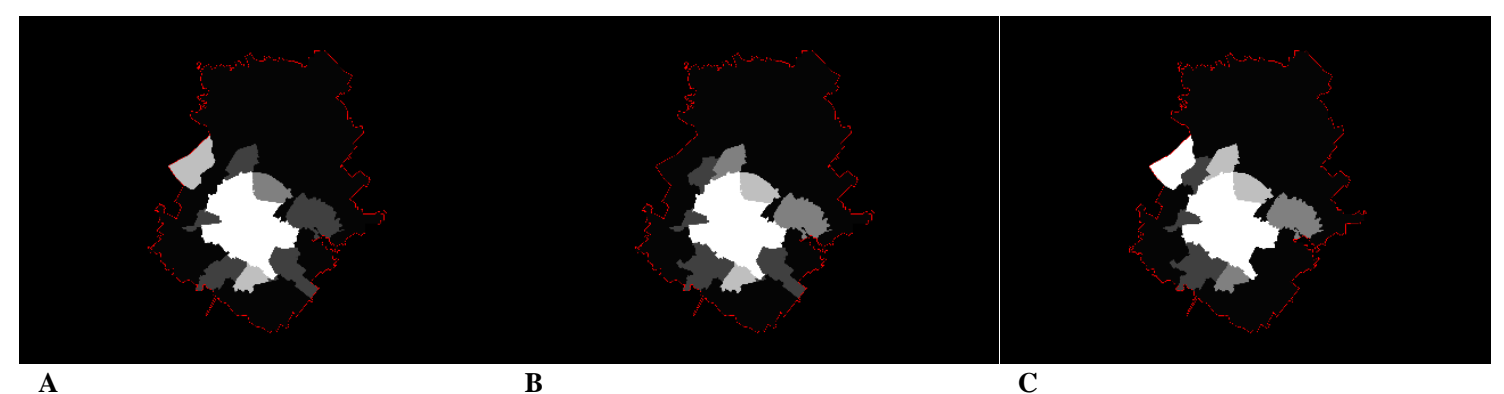



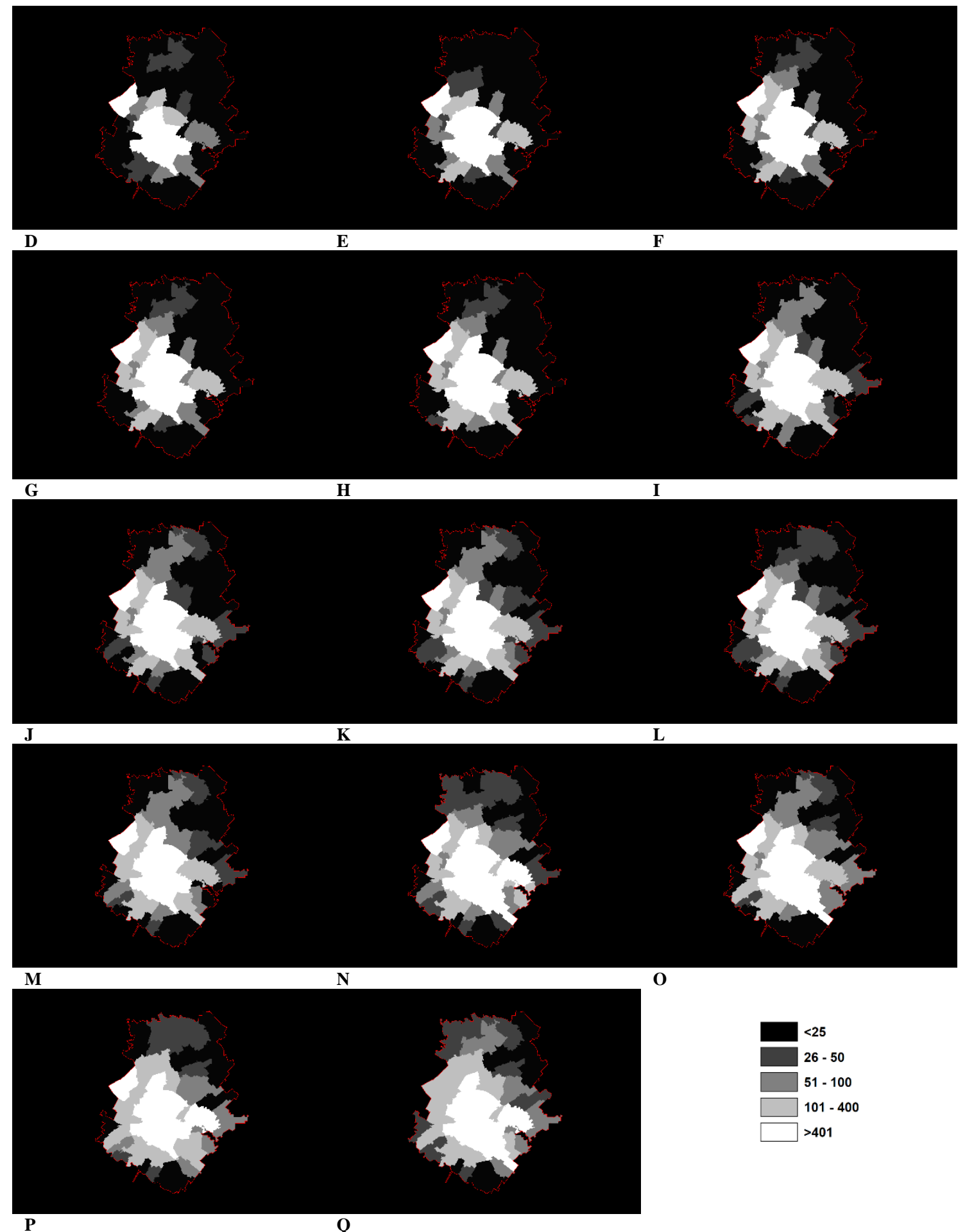

Figure 3. Distribution of the total number of employees (A - year 2000 to $\mathbf{Q}$ - year 2016)

The distribution of the total number of employees (Fig. 3) in the creative sector for the Bucharest-Ilfov Development Region shows a positive trend of the values. The city of Bucharest is the one that makes a significant contribution to the number of employees, with a value of 83.051 employees in the creative sector in 2000 out of a total of 904.560 of the development region it belongs to. Increases and decreases are observed during the 
analyzed period, reaching 2016 at the values of the employees for the Bucharest-Ilfov Development Region of 1.287.861, Bucharest accounting for 143.467 of them.
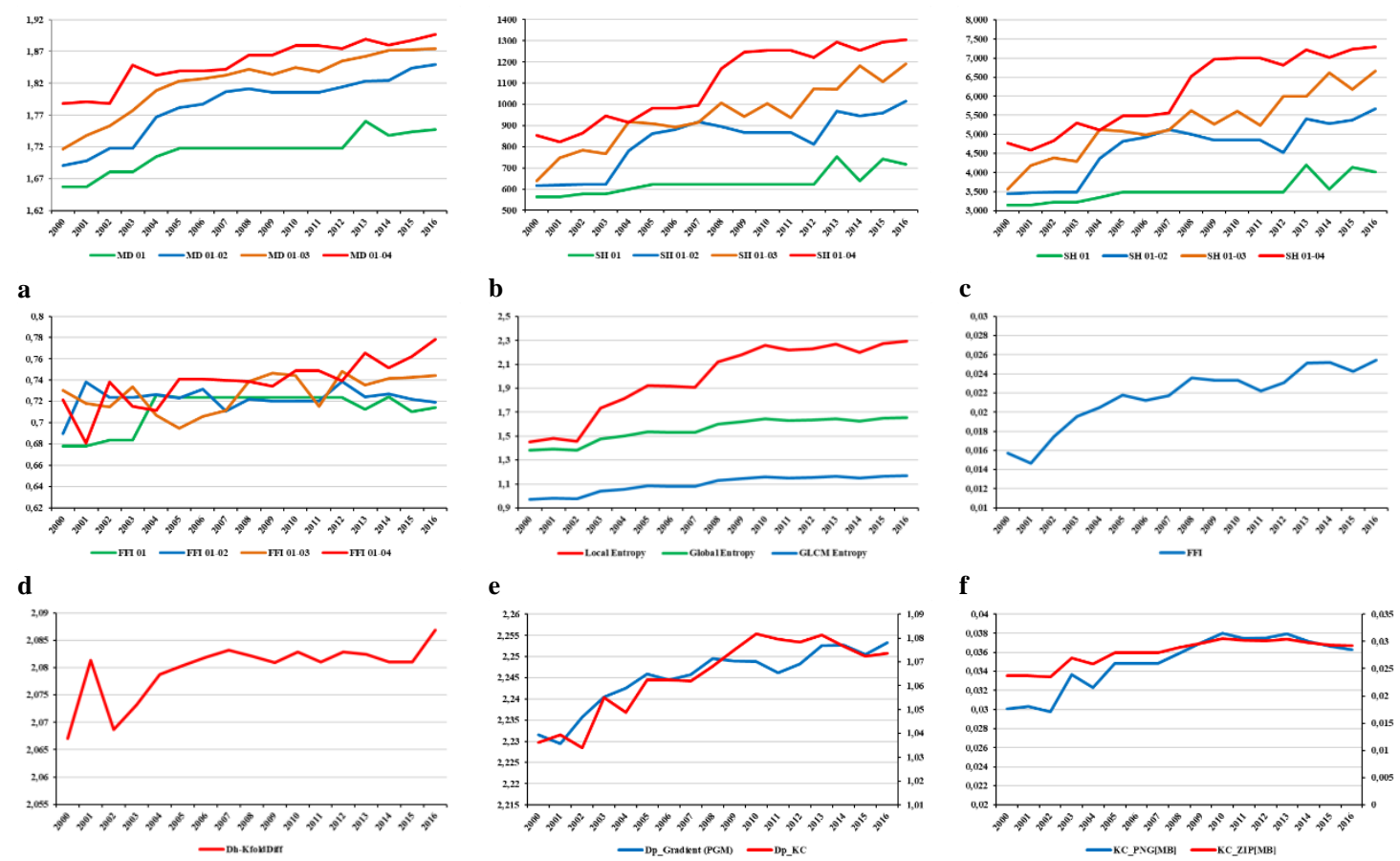

g

h

$$
\text { i }
$$

Figure 4. Dynamics of the number of employees. a. Mass Dimension; b. Sholl Dimension - number of intersections; c. Sholl Dimension - the mean of intersections; d. FFI binary; e. Entropy (local - red; global - green; GLCM - blue); f. FFI grayscale; g. Higuchi 2D; h. Pyramid Dimension (PGM - blue; $\mathrm{KC}$ - red) i. Kolmogorov complexity (PNG - blue; ZIP - red)

It is noted that the analyzes of number of employees (Fig. 4), as in the case of turnover, reveal an increase in values for class 01-04, which develops the new propagation direction. All the indicators analyzed mentioning the evolution of the number of employees on different propagation directions.

\section{CONCLUSIONS}

The study highlighted the spatial dynamics of creative economies in the most complex territorial system in Romania, Bucharest, a city that has structured around an emerging space with many specifics. Creative economies tend to expand more and more outside the polarizing center in search of competitive advantages that offset the growing distance from the urban center.

The region has grown and holds a significant share of creative employees thanks to the development of creative activities such as IT, architecture, editing and printing, advertising, gaming and gaming testing.

Fractal and non-fractal analyzes highlight the trend of expanding territorial administrative units which have high values of turnover and number of employees in creative economies.

\section{REFERENCES}

[1] Department for Culture, Media and Sport. Creative Industries Mapping Document, London: Department for Culture, Media and Sport, 2001. 
[2] Booyens I. Creative industries, inequality and social development: Developments, impacts and challenges in Cape Town, Urban Forum, vol. 23, pp. 43-60, 2012 in Zuhdi U. Analyzing the influence of creative industry sector to the national economic structural changes by decomposition analysis: The case of Indonesia, Procedia - Social and Behavioral Sciences, vol. 65, pp 980-985, 2012.

[3] United Nations. Creative Economy Report 2013, United Nations, Geneva and New York, 2013.

[4] De-Miguel-Molina B., Hervas-Oliver J.-L., Boix R. \& De-Miguel-Molina M. The importance of creative industry agglomerations in explaining the wealth of European regions, European Planning Studies, vol. 20, pp. 1263-1280, 2012 in Zuhdi U. Analyzing the influence of creative industry sector to the national economic structural changes by decomposition analysis: The case of Indonesia, Procedia - Social and Behavioral Sciences, vol. 65, pp 980-985, 2012.

[5] Dong L., \& Haruna M. The practice of urban renewal based on creative industry: Experience from the Huangjueping creative industries in Chongqing China, Journal of Sustainable Development, vol. 5, pp. 101-110, 2012 in Zuhdi U. Analyzing the influence of creative industry sector to the national economic structural changes by decomposition analysis: The case of Indonesia, Procedia - Social and Behavioral Sciences, vol. 65, pp 980-985, 2012.

[6] Haralick R., Shanmugan K., \& Dinstein I. Textural Features for Image Classification, IEEE Transactions on Systems, Man, and Cybernetics, vol. SMC-3, pp. 610-621, 1973.

[7] Radovic M., Milosevic M., Peulic A. \& Filipovic N. Application of data mining algorithms for mammogram classification, Proceedings of the 13th international IEEE conference on Bioinformatics and Bioengineering (BIBE), pp 1-4, 2013.

[8] Toma S.-G., Peptenatu D., Andronache I., Ahammer H., Pintilii R.-D., Drăghici C.-C., Simion A. G. The Creative Economy in Romania, a Key Factor of Economic Integration in the European Union, pp 329-350 in Dima A. (eds) Doing Business in Europe. Contributions to Management Science, Springer: Cham, Switzerland, 2018.

[9] Zappasodi F., Olejarczyk E., Marzetti L. \& Assenza G. Fractal Dimension of EEG Activity Senses Neuronal Impairment in Acute Stroke, PLOS ONE, vol. 9, pp 3929-3941, 2014.

[10] Huang Q., Lorch J.R.\& Dubes R.C. Can the fractal dimension of images be measured?, Pattern Recognition, vol. 27, pp 339-349, 1994.

[11] Benoit M. The fractal geometry of nature, Macmillan, 1983.

[12] Benoit M. How Long Is the Coast of Britain? Statistical Self-Similarity and Fractional Dimension, Science, vol. 156, pp 636-638, 1967.

[13] Zaletel I., Ristanović D., Stefanović B.D. \& Puškaš N. Modified Richardson's method versus the box-counting method in neuroscience, J Neurosci Methods., vol. 242, pp 93-96, 2015.

[14] Neil G. \& Curtis K.M. Shape recognition using fractal geometry. Pattern Recognit. Vol. 30, pp 1957-1969, 1997.

[15] Pintilii R.-D., Andronache C. I., Simion A.-G., Drăghici C.-C., Peptenatu D., Ciobotaru A.M., Dobrea R.-C. \& Papuc R.-M., Determining forest fund evolution by fractal analysis (Suceava - Romania), Urbanism Architecture Constructions, vol. 7, pp 31-42, 2016.

[16] Diaconu D. C., Andronache I., Ahammer H., Ciobotaru A.-M., Zelenakova M., Dinescu R., Pozdnyakov A. V. \& Chupikova S. A. Fractal drainage model - a new approach to determinate the complexity of watershed, Acta Montanistica Slovaca,vol. 22, pp 12-21, 2017.

[17] Andronache I., Fensholt R., Ahammer H., Ciobotaru A.-M., Pintilii R.-D., Peptenatu D., Drăghici C.-C., Diaconu D. C., Radulović M., Pulighe G., Azihou A. F., Toyi M. S. \& Sinsin B. Assessment of Textural Differentiations in Forest Resources in Romania Using Fractal Analysis, Forests, vol. 8, 2017. 
[18] Jelinek H.F., Cornforth D.J., Roberts A.J., Landini G., Bourke P. \& Iorio A. Image Processing of Finite Size Rat Retinal Ganglion Cells Using Multifractal and Local Connected Fractal Analysis, 2004 in Webb G.I., Yu X. (eds) Advances in Artificial Intelligence. AI 2004. Lecture Notes in Computer Science, vol. 3339. Springer, Berlin, Heidelberg, 2004.

[19] Landini G., Murray P. I. \& Misson G. P. Local connected fractal dimensions and lacunarity analyses of 60 degrees fluorescein angiograms, Investigative Ophthalmology \& Visual Science, vol. 36, pp 2749-2755, 1995.

[20] Lung C.W. \& Mu Z.Q. Fractal dimension measured with perimeter-area relation and toughness of materials, Phys Rev B Condens Matter., vol. 38, 1995.

[21] Cheng Q. The Perimeter-Area Fractal Model and Its Application to Geology, Mathematical Geology, vol. 27, 1995.

[22] Pitsianis N., Bleris G. \& Argyrakis P. Information dimension in fractal structures, Physical Review B, vol. 39, pp 7097-100, 1989.

[23] Bianciardi G. \& Pontenani F. Fractals and Pathology. Journal of Biostatistics and Biometric Applications, vol. 1, 2015.

[24] Marana A. N., Da Fontoura Costa L., Lotufo R. A., Velastin S. A. Estimating crowd density with Minkowski fractal dimension, Proceedings of IEEE International Conference on Acoustics, Speech, and Signal Processing, pp 3521-3524, 1999.

[25] Ahammer H. Higuchi dimension of digital images, PLoS ONE, vol. 6, 2011.

[26] Spasic S. On 2D generalization of Higuchi's fractal dimension, Chaos, Solitons \& Fractals,vol. 69, pp 179-187, 2014.

[27] Ahammer H., Sabathiel N. \& Reiss M. Is a two-dimensional generalization of the Higuchi algorithm really necessary?, Chaos, vol. 25, 2015.

[28] Wu Y. T., Shyu K. K., Chen T. R., Chen H. Y., Hu H. H. \& Guo W. Y.,Using 3D FFT fractal dimension estimator to analyze the complexity of fetal cortical surface from MR images, Expert Systems with Applications, vol. 37, pp 6123-6127, 2010.

[29] Grassberger P. \& Procaccia I. Measuring the Strangeness of Strange Attractors, Physica D: Nonlinear Phenomena, vol. 9, pp 189-208, 1983.

[30] Decoster G. P. \& Mitchell D. W. The efficacy of the correlation dimension technique in detecting determinism in small samples, Journal of Statistical Computation and Simulation, vol. 39, pp 221-229, 1991.

[31] Wong A., Wu L., Gibbons P. B. \& Faloutsos C. Fast estimation of fractal dimension and correlation integral on stream data, Information Processing Letters, vol. 93, pp 91-97, 2005.

[32] Peleg S., Naor J., Hartley R. \& Avnir D. Multiple resolution texture analysis and classification, IEEE Transactions on Pattern Analysis and Machine Intelligence, PAMI-vol. 6, pp 518-523, 1984.

[33] Perrier E., Tarquis A. \& Dathe A. A program for fractal and multifractal analysis of 2D binary images: computer algorithms versus mathematical theory, Geoderma, vol. 134, pp 284294, 2006.

[34] Zhou H., Perfect E., Lu Y. Z., Li B. G. \& Peng X. H. Multifractal analyses of grayscale and binary soil thin section images, Fractals, vol. 19, pp 299-309, 2011.

[35] Andronache I., Ahammer H., Jelinek H. F., Peptenatu D., Ciobotaru A. M., Draghici C. C, Pintilii R. D., Simion A. G., Teodorescu C. Fractal analysis for studying the evolution of forests, Chaos, Solitons \&Fractals, vol. 91, pp 310-318, 2016.

[36] Drăghici C.-C., Andronache I., Ahammer H., Peptenatu D., Pintilii R.-D., Ciobotaru A.-M., Simion A. G., Dobrea R. C., Diaconu D. C., Vişan M.-C. \& Papuc R. M., Spatial evolution of 
forest areas in the northern Carpathian Mountains of Romania, Acta Montanistica Slovaca, vol. 22, pp 95-106, 2017.

[37] Pintilii R.-D., Andronache I., Diaconu D. C., Dobrea R. C., Zeleňáková M., Fensholt R., Peptenatu D., Drăghici C.-C., Ciobotaru A.-M., Using fractal analysis in modelling the dynamics of forest areas and economic impact assessment, Maramures County Romania as a case study, Forests, vol. 8, 2017.

[38] https://imagej.nih.gov/ij/docs/guide/146-29.html

[39] Schneider C. A., Rasband W. S. \& Eliceiri K. W. NIH Image to ImageJ: 25 years of image analysis, Nature methods, vol. 9, pp 671-675, 2012.

[40] http://www.trusoft-international.com/benoit.html

[41] Kainz P., Mayrhofer-Reinhartshuber M. \& Ahammer H. IQM: An Extensible and Portable Open Source Application for Image and Signal Analysis, PLoS ONE, vol. 10, 2015.

[42] Sholl D.A. Dendritic organization in the neurons of the visual and motor cortices of the cat, J. Anat., vol. 87, pp 387-406, 1953.

[43] https://imagej.net/Sholl_Analysis

[44] Ferreira T., Blackman A., Oyrer J., Jayabal A., Chung A., Watt A., Sjöström J. \& van Meyel D. Neuronal morphometry directly from bitmap images, Nature Methods, vol. 11, pp 982-984, 2014.

[45] https://sourceforge.net/projects/iqm-plugin-ffi/

[46] Ahammer H. \& Mayrhofer-Reinhartshuber M. Image pyramids for calculation of the box counting dimension, Fractals, vol. 20, pp 281-293, 2012.

[47] Mayrhofer-Reinhartshuber M., Kainz P. \& Ahammer H. Image Pyramids as a new Approach for the Determination of Fractal Dimensions, Proceedings of the 2013 2nd International Conference of Pattern Recognition Applications and Methods, pp 239-243, 2013.

[48] Haralick R., Shanmugan K. \& Dinstein I. Textural Features for Image Classification., IEEE Transactions on Systems, Man, and Cybernetics, vol. SMC-3, pp. 610-621, 1973.

[49] Spasic S. On 2D generalization of Higuchi's fractal dimension, Chaos, Solitons \& Fractals, vol. 69, pp 179-187, 2014.

[50] Ahammer H., Sabathiel N. \& Reiss M. A. Is a two-dimensional generalization of the Higuchi algorithm really necessary?, Chaos, vol. 25, 2015.

[51] Mayrhofer-Reinhartshuber M. \& Ahammer H. Pyramidal fractal dimension for high resolution images, Chaos, vol. 26, 2016.

[52] Kolmogorov A. On Tables of Random Numbers, Theoretical Computer Science, vol. 207, pp 387-395, 1998. 